\title{
The relationship between central corneal thickness and corneal curvature in adult Nigerians
}

\section{E Iyamu† and NM Eze:}

\author{
$\dagger,+$ Department of Optometry, Faculty of Life Sciences, University of Benin, Benin City, Edo State, \\ Nigeria
}

${ }^{\dagger}<$ eghosaiyamu@yahoo.com>

${ }^{\dagger}<$ eghosa.iyamu@gmail.com>

\begin{abstract}
Purpose: The aim of this study was to provide average values for central corneal thickness (CCT) and corneal curvature (CC) and also to determine a regression model for the relationship between $\mathrm{CCT}$ and $\mathrm{CC}$ in adult Nigerians without glaucoma.

Methods: A total of 95 subjects consisting of 56 males and 39 females aged between 20 and 69 years with mean age of $47.1 \pm 14.1$ years were recruited for the study. Central corneal thickness was measured by ultrasound pachymetry (SW-1000P ultrasound pachymeter, Tianjin Suowei Electronic Technology, China) and corneal curvature was measured by keratometry (Bausch \& Lomb keratometer H-135A, USA).
\end{abstract}

Results: The average values of $550.1 \pm 33.1 \mu \mathrm{m}$ and $43.0 \pm 1.1 \mathrm{D}$ were obtained for CCT and CC respectively. CCT significantly correlated with age $(p=0.01)$, and the regression model predicts a decrease of $6.0 \mu \mathrm{m}$ in CCT per decade. No significant association was found between $\mathrm{CC}$ and age $(p=0.56)$. Also, no significant association was found between CCT and CC $(p=0.07)$. Female subjects had significantly steeper corneas than their male counterparts.

Conclusion: Central corneal thickness decreases with increasing age. Neither CCT nor age appear to be significantly correlated with corneal curvature. (S Afr Optom 2011 70(1) 44-50)

Key words: Central corneal thickness, ultrasound pachymetry, corneal curvature, keratometry

\section{Introduction}

Central corneal thickness is an index for assessing the corneal health status ${ }^{1}$. The determination of corneal thickness has gained relevance in recent years, partly due to the growing interest in the continued use of contact lenses, refractive surgery and the early identification of those who are at a higher risk of developing primary open angle glaucoma. Corneal thickness provides valid information about its physiological condition and possible changes associated with diseases, traumas, and hypoxia. The di- urnal variation of corneal thickness is an obstacle for repeated pachymetric measurements. A diurnal variation of $10 \mu \mathrm{m}$ for the central thickness and $20 \mu \mathrm{m}$ in the periphery at $40^{\circ}$ was reported by Kiely et $a l^{2}$. It has been shown that central corneal thickness is a better predictor than intraocular pressure in identifying those at higher risk of developing primary openangle glaucoma when combined with some other risk factors. ${ }^{3}$ Central corneal thickness is used to measure corneal rigidity, thus, it consequently has an impact on the accuracy of intraocular pressure by applanation tonometry ${ }^{4}$. Studies have shown that intraocular 
pressure measurements by applanation tonometry are affected by central corneal thickness, corneal curvature and axial length ${ }^{5,6}$. Corneal curvature is usually used for intraocular lens calculation and corneal refractive surgery, contact lens fitting and detection of higher astigmatism. Cavallini and colleagues ${ }^{7}$ found a highly significant correlation in the distribution of corneal thickness and the radius of curvature of the anterior surface of the cornea along the principal meridians (horizontal and vertical). Shimmyo et al ${ }^{8}$ found a significant correlation between central corneal thickness and corneal curvature. Cho and Lam ${ }^{9}$ reported no significant relationship between central corneal thickness and corneal curvature.

The aim of this study was to investigate the association between central corneal thickness and corneal curvature in a Nigerian population. To the best of our knowledge, no study has exclusively considered the relationship between these variables.

\section{Methods}

This observational, prospective, cross-sectional study was conducted in the Optometry clinic at the University of Benin, Nigeria over a period of six months (August 2009 and January 2010). All subjects fulfilled the inclusion criteria: no history of corneal infection or abnormalities, contact lens wear, systemic disease (such as diabetes or rheumatoid arthritis), ocular trauma or surgery. The subjects intraocular pressure had to be between $10-21 \mathrm{mmHg}$. Subjects were aged between 20-69 years and were placed in one of four age groups (20-39, 40-49, 50-59 and 6069 years). All the procedures were approved by the Departmental Research and Ethics Committee of the University in accordance with the Helsinki Declaration of human subjects. The Bausch and Lomb keratometer H-135A (Bausch \& Lomb Technology, USA) was used to measure the corneal curvature. Average corneal curvature (AVK) was obtained by the average of the horizontal and vertical corneal curvature. The central corneal thickness was measured with SW-1000P ultrasound pachymeter (Tianjin Suowei Electronic Technology, China). The intraocular pressure was assessed by non-contact tonometry (Keeler Pulsair EasyEye tonometer). All measurements were taken between 9 am and 12 noon.

Procedure for keratometry: the eyepiece or reticule was adjusted for the examiner's refractive status. The subject was seated comfortably before the instrument with forehead on the headrest and the chin fitting snugly into the chinrest. The leveling sight pin was at the same level as the outer canthus of the eye to be assessed. At this point the instrument was switched on and the examiner viewed the mire through the eyepiece while patient was asked to fixate on the reflection of his/her own eye. The blurred mire was cleared by adjusting the focusing knob. The cross-hair was placed in the centre of the focusing circle to ensure that the optical axis of the instrument was coincident with the visual axis of the patient to ensure accuracy of readings by adjusting the elevation knob. Once the exact position was obtained the lock knob was tightened so that the instrument does not rotate out of setting. The minus signs are superimposed with the vertical power drum and the plus signs with the horizontal power drum. Three measurements were taken and the average values for vertical and horizontal corneal curvatures were recorded along the appropriate meridians. The average of both values was recorded as the average corneal curvature (AVK).

For pachymetry, subject was comfortably seated with the head upright and eyes in the primary position of gaze. The probe was sterilized with $70 \%$ alcohol and allowed to air-dry. A drop of topical anaesthetic (Tetracaine $\mathrm{HCl} 0.1 \%$ ) was instilled in subject's eye. The probe was carefully aligned perpendicularly to and lightly applanating the cornea. At least ten readings are continuously taken and the average calculated as the measured central corneal thickness.

\section{Data analysis}

All data were analyzed on computer (Statgraphics ${ }^{\circledR}$ Plus ver., 5.1; Statistical graphics Corp, USA and SPSS ver., 15.0; SPSS Inc., Chicago, IL, USA). Measures of spread including standardized kurtosis and standardized skewness were derived. Normality of distribution of data was determined by the spread. The distribution of data was considered normal when the values of the spread lie between -2 and 2. Oneway analysis of variance (ANOVA) was used to compare the mean corneal curvature and central corneal thickness across age groups. The correlation between variables was tested using linear regression analysis. A $p$ value of $\leq 0.05$ was taken as statistically significant. 


\section{Results}

A total of ninety-five subjects with mean age 47.1 \pm 14.1 years (range, 20-69 years) consisting of 56 males and 39 females were recruited for this study. The mean CCT, AVK, horizontal corneal and curva- ture are as presented in Table 1 below.Analysis of variance (ANOVA) performed on the mean CCT across age groups, shows that the difference in mean was not statistically significant $(F=0.18, d f=3, p=0.15)$. Table 2 shows the descriptive statistics of CCT across age groups.

Table 1 Descriptive statistics of the measured variables

\begin{tabular}{lcccc}
\hline & \multicolumn{3}{c}{ Measured variables } \\
Statistics & CCT $(\mu \mathrm{m})$ & AVK $(\mathrm{D})$ & HK (D) & VK (D) \\
\hline Count & 95 & 95 & 95 & 95 \\
Average & 550.1 & 43.0 & 42.9 & 43.2 \\
SD & 33.1 & 1.1 & 1.1 & 1.0 \\
Range & $478.0-662.0$ & $40.0-45.8$ & $40.3-45.5$ & $39.8-46.0$ \\
Stnd skew & 2.0 & -0.3 & -0.5 & -0.1 \\
Stnd kurt & 2.0 & -0.1 & 0.2 & 0.3 \\
95\% CI & $543.4-556.9$ & $42.8-43.3$ & $42.7-43.1$ & $42.9-43.4$ \\
\hline
\end{tabular}

$\mathrm{SD}=$ standard deviation; Stnd skew=standardized skewness; Stnd kurt=standardized kurtosis; CI=confidence interval; $\mathrm{AVK}=$ average corneal curvature; $\mathrm{HK}=$ horizontal corneal curvature; $\mathrm{VK}=$ vertical corneal curvature

Table 2 Descriptive statistics of central corneal thickness across age groups

\begin{tabular}{lcccc}
\hline & \multicolumn{4}{c}{ Age groups (years) } \\
Statistics & $20-39$ & $40-49$ & $50-59$ & $60-69$ \\
\hline Count & 28 & 21 & 21 & 25 \\
Average & 561.3 & 548.3 & 548.1 & 540.9 \\
SD & 28.1 & 24.5 & 41.9 & 34.5 \\
Range & $506.0-623.0$ & $491.0-604.0$ & $487.0-662.0$ & $478.0-609.0$ \\
Stnd skew & 0.4 & 0.9 & 2.6 & -0.2 \\
Stnd kurt & -0.1 & 1.4 & 2.0 & -0.5 \\
$95 \%$ CI & $550.4-572.2$ & $537.2-559.5$ & $529.0-567.2$ & $526.6-555.1$ \\
\hline
\end{tabular}


ANOVA performed on the mean HK across the age groups shows no significant difference $(F=0.13$, $d f=3, p>0.05)$. Similarly, the difference in mean VK across age groups was not significant $(F=0.47, d f=3$, $p=0.70$ )

The difference in mean CCT between males and females was not statistically significant (Unpaired $t$ - test: $t=1.48, p=0.70)$. Table 4 shows the descriptive statistics of CCT in male and female subjects.

Gender-related difference in mean AVK was statistically significant $(t=2.38, d f=93, p=0.02)$, with females showing steeper corneas than their male counterparts Table 5 shows the statistics of corneal curvature according to gender.

Table 4 Descriptive statistics of central corneal thickness according to gender

\begin{tabular}{|c|c|c|c|}
\hline Statistics & Males & Gender & Females \\
\hline Count & 56 & & 39 \\
\hline Average & 552.0 & & 544.5 \\
\hline $\mathrm{SD}$ & 36.4 & & 28.8 \\
\hline Range & $487.0-662.0$ & & $478.0-636.0$ \\
\hline Stnd skew & 0.8 & & 1.7 \\
\hline Stnd kurt & 0.9 & & 2.0 \\
\hline $95 \% \mathrm{CI}$ & $542.5-561.4$ & & $535.2-553.8$ \\
\hline
\end{tabular}

Table 5 Descriptive statistics of Average corneal curvature according to gender

\begin{tabular}{|c|c|c|c|}
\hline Statistics & Males & $\pi \mathrm{C}$ & Females \\
\hline Count & 56 & Gender & 39 \\
\hline Average & 42.8 & & 43.3 \\
\hline $\mathrm{SD}$ & 1.1 & & 1.1 \\
\hline Range & $40.0-45.4$ & & $41.0-45.8$ \\
\hline Stnd skew & -0.2 & & 0.2 \\
\hline Stnd kurt & 0.1 & & -0.3 \\
\hline
\end{tabular}


Regression analysis performed on CCT and age shows a statistically significant negative association between them $\left(r=-0.27, r^{2}=7.14 \%, p=0.01\right)$. The linear regression model is represented by: $\mathrm{CCT}=578.1$ $-0.61 \mathrm{AGE}$. The model as fitted explains $7.14 \%$ of the variability in CCT. From the regression model, a 10year increase in age would lead to approximately 6.0 $\mu \mathrm{m}$ decrease in CCT. The association between CCT and age is represented by Figure 1.

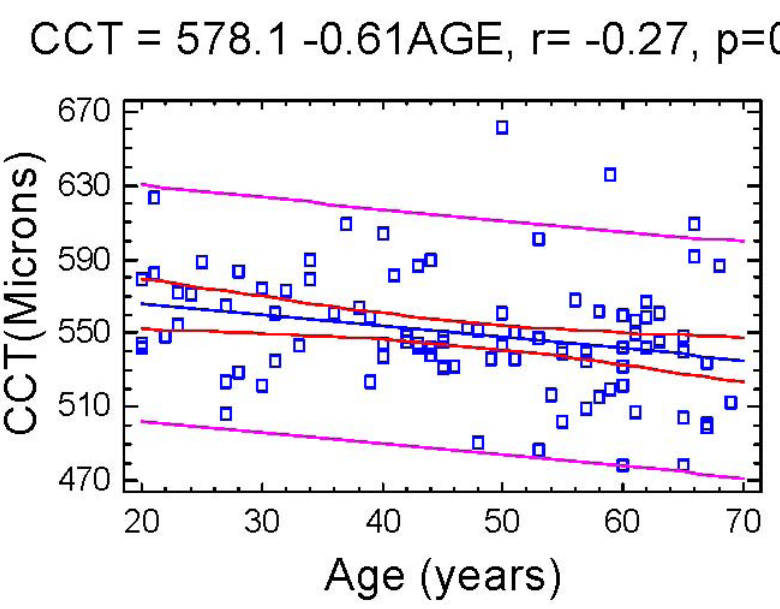

Figure 1 Correlation of central corneal thickness and age, with the $95 \%$ confidence interval of the linear regression line

However, the association between average corneal curvature and age was not statistically significant $(r=0.06, p=0.56)$. Figure 2 shows the regression line and the $95 \%$ confidence interval of the regression line.

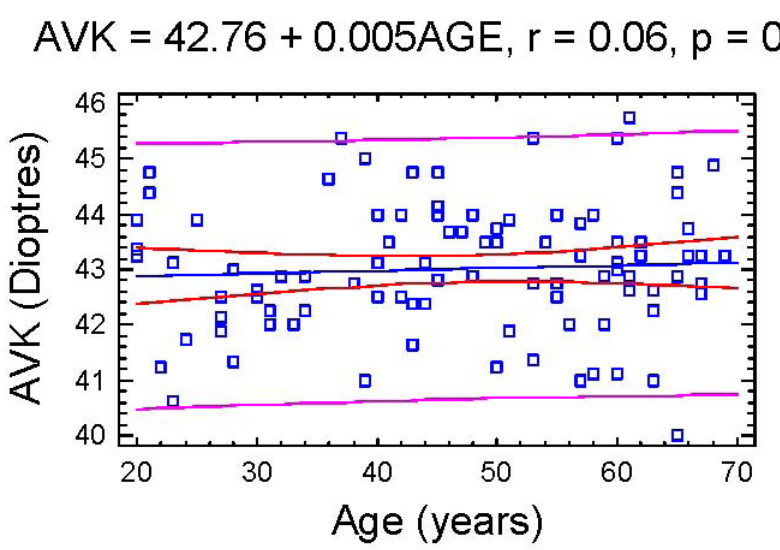

Figure 2 Correlation of average corneal curvature and age, linear regression line and $95 \%$ confidence interval
Similarly, the correlation between CCT and AVK was not statistically significant $(r=0.18$, $\left.r^{2}=3.3 \%, p=0.07\right)$. The linear regression equation is: $\mathrm{CCT}=332.13+5.05 \mathrm{AVK}$. From the linear regression model, an increase of $1.0 \mathrm{D}$ in corneal curvature would lead to approximately $5.0 \mu \mathrm{m}$ decrease in CCT. Figure 3 shows the association between the CCT and AVK.



Figure 3 Correlation of central corneal thickness and average corneal curvature showing the linear regression with the $95 \%$ confidence interval of the regression line

\section{Discussion}

There has been an increasing interest in determining the values and differences in normal CCT, especially as it is known to play a vital role in refractive surgery such as Laser In Situ Keratomileusis (LASIK), photorefractive keratectomy $(\mathrm{PRK})^{9}$, and in the diagnosis and management of glaucoma ${ }^{3}$. Among the several factors that have been shown to affect central corneal thickness are ethnicity, age, gender and instrumentation. The reason for carrying out this study was to provide preliminary average values of central corneal thickness and corneal curvature, for the adult Nigerian population. The aim of the study was also to provide a regression equation that can be employed to predict the relationship between central corneal thickness and corneal curvature in black African population. This study shows a mean CCT of 550.2 $\pm 33.1 \mu \mathrm{m}$ for the study. Previous studies have reported mean CCT among Nigerians to range from 535.0 to $557.45 \mu \mathrm{m} .{ }^{3}$, 10, 11 Reported mean CCT among African-Americans range from 521.0 to $555.0 \mu \mathrm{m}^{8,12-15}$. The difference in mean values of CCT reported for African-Americans 
as compared to the mean value obtained in this study may have been due to the heterogeneous nature of the African-American population. The analysis from this study shows that CCT decreases with age. The mean $\operatorname{CCT}(540.9 \pm 34.5 \mu \mathrm{m})$ of $60-69$ years old in the present study is similar to the average value (535.0 $\pm 38.0 \mu \mathrm{m}$ ) reported by Mercieca et al ${ }^{10}$ for Nigerians. Age is statistically significantly related to CCT. The regression analysis carried out to investigate the predictive power of age on CCT showed a negative relationship. The linear model of the relationship was represented by the equation: $\mathrm{CCT}=578.1-0.61 \mathrm{AGE}$. According to the model, a 10-year increase in age would lead to approximately $6.0 \mu \mathrm{m}$ decrease in CCT. Mercieca et al ${ }^{10}$ and Hahn et al ${ }^{1}$ reported that decreasing values of CCT were significantly related to older age. However, they did not present the regression equation for the prediction of CCT with increasing age. Durkin and colleagues ${ }^{16}$ reported that older age was significantly correlated with having a thinner central cornea $(r=-0.24, p=0.001)$ among the Aboriginal people of South Australia. Aghaian et al ${ }^{14}$ claimed that there was an inverse relationship between age and CCT $(r=-0.13, p=0.0002)$. In their study population that comprised Asians, Caucasians, Hispanics, and African-Americans, the CCT decreases by $3.0 \mu \mathrm{m}$ per decade. In this study, the average corneal curvature is taken as the true measurement of the corneal curvature.

The mean corneal curvature of the study population was $43.0 \pm 1.1 \mathrm{D}$, and the corneal curvatures (CCs) across the various age groups are represented in Table 2. Age group was not significantly related to corneal curvature. The regression analysis carried out to determine the predictive power of age on $\mathrm{CC}$ showed no significant association. The linear regression model was represented by: $\mathrm{CC}=42.78+0.005 \mathrm{AGE}$.

The gender-related difference in corneal curvature was statistically significant $(t=-2.38, p=0.02)$, with female subjects having slightly steeper corneas than their male counterparts. The tendency for females to have steeper corneas may be related to the fact that females have shorter axial length than males. Smaller eyes are associated with steeper corneas ${ }^{17-19}$. Linear regression analysis shows no relationship between CCT and corneal curvature $(r=0.18, p=0.07)$. This finding was consistent with the findings of Eysteinsson et $a l^{17}$, Kohlhaas et al ${ }^{20}$, Francis et $a l^{21}$, Cho and $\mathrm{Lam}^{9}$, who reported no significant association between CCT and corneal curvature. However, Shimmyo et $a l^{8}$ and Sawada et al ${ }^{8}$ reported that CCT was positively correlated with corneal curvature in Americans and Japanese. A weak correlation between CCT and corneal curvature was also demonstrated by the studies of Suzuki et $a l^{23}$ and Tong et al24.

In conclusion, central corneal thickness was negatively correlated with age. The relationship between central corneal thickness and corneal curvature was not significant in the study population.

\section{References}

1. Hahn S, Azen S, Ying-Lai M, Varma R, Los Angeles Latino Eye study group (2003). Central corneal thickness in Latinos. Invest Ophthalmol Vis Sci 2003 44(4) 1508-1512.

2. Kiely PM, Carney LG. Diurnal variations of corneal topography and thickness. Am J Optom Physiol Opt 1982 59(12) 976-982.

3. Iyamu E, Ituah I. The relation between central corneal thickness and intraocular pressure: A comparative study of normals and glaucoma subjects. Afr J Med Sci Am 2008 37(4) 345-353.

4. Goldmann H, Schmidt TH. Uber Applanation tonometrie. Ophthalmologica 1957134 221-242.

5. Whitacre MM, Stein R. Sources of error with use of Goldmann-type tonometers. Surv Ophthalmol 199338 1-30.

6. Whitacre MM, Stein RA, Hassanein K. The effect of corneal thickness on applanation tonometry. Am J Ophthalmol 1993 115 592-596.

7. Cavallini L, Longanesi GM, Toni R. Quantitative clinical anatomy of the human cornea in vivo. Acta Anatomica 1996 157 73-79.

8. Shimmyo M, Ross AJ, Moy AJ, Mostafavi B. Intraocular pressure, Goldmann applanation tension, cornea thickness, and corneal curvature in Caucasians, Asians, Hispanics, and African Americans. Am J Ophthalmol 2003136 603-611.

9. Cho P, Lam C. Factors affecting the central corneal thickness of Hong Kong Chinese. Curr Eye Res 199918 368-374

10. Mercieca K, Odogu V, Fiebai B, Arowolo O, Chukwuka F. Comparing central corneal thickness in a sub-Sahara cohort to African Americans and Afro-Caribbeans. Cornea 2007 26(5) 557-560.

11. Iyamu E, Odudu T, Udom E. Changes in central corneal thickness and corneal curvature after daily wear soft contact lens in young adult Nigerians. Sud J Ophthalmol 2010 2(1) 20-26.

12. Brandt JD, Beisser JA, Kass MA, Gordon MO. Central corneal thickness in ocular Hypertension Treatment Study (OHTS). Ophthalmology $2001 \mathbf{1 0 8}$ 1779-1788.

13. La Rosa FA, Goss RL, Orengo-Nania S. Central corneal thickness of Caucasians and African Americans in glaucomatous and non-glaucomatous populations. Arch Ophthalmol 2001110 123-127. 
14. Aghaian E, Choe JE, Lin S, Stamper RL. Central corneal thickness of Caucasians, Chinese, Hispanics, Filipinos, African Americans, and Japanese in a glaucoma clinic. Ophthalmology 2004111 2211-2219.

15. Hussein MAW, Paysee EA, Bell NP, Coats DK, Brady Mcgreery KM, Koch DD, Orengo-Nania S, Baskin D, Wilhelmus KR. Corneal thickness in children. Am J Ophthalmol 2004138 744-748.

16. Durkin SR, Tan EWH, Casson RJ, Selva D, Newland HS. Central corneal thickness among Aboriginal people attending eye clinics in remote South Australia. Clin Exp Ophthalmol 200735 728-732.

17. Eysteinsson T, Jonasson F, Sasaki H, Armarsson A, Sverrisson T, Sasaki K, Stefansson E. Central corneal thickness, radius of curvature and intraocular pressure in normal subjects using non-contact techniques: Reykjavik Eye Study. Acta Ophthalmol Scand 200280 11-15.

18. Wong ACM, Wong CC, Yuen NSY, Hui SP. Correlational study of central corneal thickness measurements on Hong Kong Chinese using optical coherence tomography, Orbscan and ultrasound pachymetry. Eye 2002 16(6) 715-721.

19. Chen MJ, Liu YT, Tsai CC, Chen YC, Chou CK, Lee SM. Relationship between central corneal thickness, refractive error, corneal curvature, anterior chamber depth and axial length. J Chin Med Assoc 2009 72(3) 133-137.

20. Kohlhaas M, Boehm AG, Spoeri E, Pursten A, Grein HJ, Pillunat LE. Effect of central corneal thickness, corneal curvature, and axial length on applanation tonometry. Arch Ophthalmol 2006124 471-476.

21. Francis BA, Hsieh A, Lai MY, Chopra V, Pera F, Azen S, Varma R, Los Angeles Latino Eye study Group. Effect of corneal thickness, corneal curvature, and intraocular pressure level on Goldmann applanation tonometry and dynamic contour tonometry. Ophthalmology 2007114 20-26.

22. Sawada A, Tomidokoro A, Araie M, Iwase A, Yamato T (2008). Refractive errors in an elderly Japanese population: the Tajimi study. Ophthalmology 2008 115 363-370.

23. Suzuki S, Suzuki Y, Iwase A, Araie M. Corneal thickness in an ophthalmologically normal Japanese population. Ophthalmology 2005112 1327-1336.

24. Tong L, Saw SM, Siak JK, Gazzard G, Tan D. Corneal thickness determination and correlates in Singaporean school children. Invest Ophthalmol Vis Sci 200445 4004-4009. 